\title{
Did the 2007 welfare reforms for low income parents in Australia increase welfare exits?
}

\author{
Yin King Fok and Duncan McVicar
}

\author{
* Correspondence: dmcvicar@ \\ unimelb.edu.au \\ Melbourne Institute of Applied \\ Economic and Social Research, \\ University of Melbourne, Melbourne, \\ Vic 3010, Australia
}

\begin{abstract}
This paper examines the impacts of recent Australian welfare to work reforms for low-income parents of school-aged children who had been in receipt of Parenting Payment - the main welfare payment for this group - for at least one year. Specifically, the reforms introduced a requirement to engage in at least 15 hours of work-related activity per week from the youngest child's seventh birthday. As was the case for similar reforms introduced by US states in the 1990s, these reforms had large, statistically significant and positive impacts on the hazard rates for exiting the welfare payment. Two thirds of these exits were exits from welfare altogether and one third were exits to other welfare payments.
\end{abstract}

JEL: 138, J22

Keywords: Welfare reform, Welfare to Work, Activation, Lone parents, Labour supply, Australia

\section{Introduction}

A long standing concern with means-tested social welfare payments for low income families with school-age children is that they can reduce incentives to participate in the labour market, potentially leading to long episodes of welfare dependence, depreciation of human capital, and ultimately exacerbating rather than alleviating poverty. Policy makers across the OECD have responded to this concern by reforming programs to encourage or compel welfare-recipient parents of all but the youngest children to either re-enter the labour market or to engage in activities aimed at maintaining or improving their employability (see Carcillo and Grubb, 2006). For example, widespread reforms along these lines were introduced across US states in the 1990s. These US welfare reforms have been extensively evaluated, and the bulk of evidence suggests they resulted in large and statistically significant falls in welfare caseloads along with increases in employment (see Blank, 2002; Grogger and Karoly, 2005; Moffitt, 2008). ${ }^{1}$ Evidence on the impact of similar types of reforms introduced outside of the US, however, is less extensive (Finn and Gloster, 2010).

This paper examines the impact of recent (2007) welfare reforms for low-income parents in Australia (mostly but not only single mothers) on the hazard rates for exiting welfare and for switching between welfare payments. By setting a requirement to engage in 15 hours per week of paid work or work-related activity for those in receipt of Parenting Payment (PP) - the main income support payment for this group with a youngest child aged seven or older, the reforms involved a substantial tightening

(c) 2013 Fok and McVicar; licensee Springer. This is an Open Access article distributed under the terms of the Creative Commons Attribution License (http://creativecommons.org/licenses/by/2.0), which permits unrestricted use, distribution, and reproduction in any medium, provided the original work is properly cited. 
of payment conditionality, broadly in line with the additional conditionality introduced by a number of US states as part of the 1990s welfare reforms. ${ }^{2}$

Ours is the first study of the impact of these 2007 reforms, and because welfare reform for low-income parents continues to be very high on the policy agenda both in Australia and across the OECD, the paper makes a contribution to both the Australian and the international welfare reform evidence base. What was the impact of these US-style welfare reforms in the rather different labour market context offered by Australia, where minimum wages are comparatively high (see OECD, 2012) and employment rates for mothers of pre-school-age children are comparatively low (see OECD, 2007)? The welfare system is also rather different in Australia compared to the US welfare system of the 1990s, with other welfare payments, not all of which have similar activity requirements, also potentially available (e.g. see DEEWR, 2008). This raises the possibility that tightening one part of the welfare system may end up shifting claimants onto other forms of welfare payment.

Further, the age-based coverage of these reforms enables credible identification of their impacts using a simple difference-in-differences approach. We find a large impact on the hazard rates for both exiting welfare and switching from PP to other welfare payments. For low-income parents covered by the new participation requirements when their youngest child turned seven, our estimates suggest that the welfare exit hazard increased by 48 percent and the welfare switching hazard more than doubled, albeit from a lower base, increasing by 114 percent. As a consequence, over the first year of the new regime the caseload for those parents with a youngest child aged 6 at the start of the year fell by 23.5 percent; without activation we estimate it would have fallen by 18.5 percent. Almost two thirds of this impact is accounted for by exits from welfare rather than welfare switches. Note also that these impacts appear larger for partnered parents than for single parents - unusually for evaluation studies both groups were covered by the same set of reforms ${ }^{3}$ - although not statistically significantly so.

The remainder of this paper is set out as follows. The following section provides further details on PP, the pre-reform welfare regime and the 2007 reforms. Section 3 briefly discusses evaluations of earlier reforms for low income parents in Australia and elsewhere. Section 4 summarises the data used for the analysis, which are taken from an administrative database longitudinally tracking welfare recipients over time (the Research Evaluation Dataset, or RED), and presents preliminary estimates of the reform impacts. Section 5 presents the econometric model and discusses identification. Section 6 presents and discusses the estimation results and section 7 concludes.

\section{Parenting payment and the 2006 and 2007 welfare reforms}

The main means-tested social welfare payment for low-income families with young children in Australia is known as Parenting Payment (PP), either Parenting Payment Single (PPS) for lone parents, or Parenting Payment Partnered (PPP) for partnered parents where the combined household income falls below a given threshold. These payments are part of the overall Income Support (IS) system, which includes welfare payments for unemployed workers, for the disabled and for a variety of other groups.

Prior to 2003, receipt of PP was not conditioned on any form of participation for those with a child under 16 years, although voluntary programs were available, 
including the Jobs, Education and Training (JET) Program, which combined an initial interview with a Centrelink ${ }^{4}$ advisor with other measures including career counselling, job search assistance, and short training courses (for details see Banks, 2005). Limited conditionality - compulsory attendance at an annual interview with a Centrelink advisor - was introduced in 2003 for those whose youngest child was aged six years or older. ${ }^{5}$ More demanding participation conditions for those with a youngest child aged 13-15 years - compulsory Mutual Obligation participation in 150 hours of approved activities such as work schemes, job search or training every 26 weeks of PP receipt, and a requirement to report activity every three months - were also introduced in 2003 (Banks, 2005). This was the regime in place until the 2006 welfare to work reforms.

Since $1^{\text {st }}$ July 2006 new claimants only qualify for PP if their youngest child is aged under eight years (PPS) or under six years (PPP). New claimant parents whose youngest child is older, or with a youngest child who turns six/eight during a welfare episode, are no longer eligible for PP but may be eligible for (less generous) unemployment benefits (New Start Allowance (NSA)). Receipt of NSA for this group is conditional on meeting part-time participation requirements of 15 hours per week in paid employment, training or employment-related activities such as job search, in addition to NSA Mutual Obligation requirements after 26 weeks. New entrant PPS recipients with a youngest child aged six years or older have also been required to meet similar part-time participation requirements since the 2006 reforms. Within the overall guidelines the precise nature of the requirements can be tailored to the particular PP recipient and are set out in a semicontractual form known as an Activity Agreement, drawn up between the individual and the Centrelink advisor. ${ }^{6}$ Failure to comply with these requirements, in the absence of any temporary exemption which may be granted for reasons such as ill health of the recipient or of a child, triggers a series of warnings and ultimately, suspension of payments.

This paper focuses not on new entrants to PP, however, but on the cohort of lowincome parents already in receipt of PP as of $30^{\text {th }}$ June 2006, i.e. the stock of existing PP recipients at the time of the 2006 reforms. This group - consisting of around 600,000 individuals - were 'grandfathered' and, provided they continued to meet the means-testing requirements for PP, and provided they didn't lose their grandfathered status by exiting IS or by changing their partnered status, remained eligible for PP until their youngest child turned $16 .^{7}$

This grandfathered cohort of parents was granted a grace period before being required to meet the new part-time participation requirements. The original intention was that this grace period would be for one year, with the new part-time participation requirements introduced for those whose youngest child was aged seven years or older, on $1^{\text {st }}$ July $2007 .^{8}$ In practice, however, participation requirements were phased in, for those with a youngest child already aged seven or older, over a period of around twelve months from July 2007, with those deemed furthest from the labour market 'activated' first. Activation involved a call to interview with a Centrelink advisor during which the new participation requirements were explained and, in most cases, an Activity Agreement setting out how the individual would meet the requirements drawn up and signed there and then. ${ }^{9}$ The rest of this group either signed an Activity Agreement at a later date (e.g. because of a temporary exemption) ${ }^{10}$, exited PP following the interview but before signing an Activity Agreement, or were yet to sign an Activity Agreement by the last date for which we have data ( $30^{\text {th }}$ June 2009). ${ }^{11}$ 
Unfortunately, this non-random phasing-in of the participation requirements, together with inaccuracies and missing values in the recording of interview and agreement dates, makes identification of the impact of the reforms difficult for those in the grandfathered group with children already aged seven years or older as of $1^{\text {st }}$ July 2007 . Instead we primarily exploit information on those in the grandfathered group with a youngest child aged under seven as of $1^{\text {st }}$ July 2007, but who then subsequently turned seven within our sample period. All parents in this category were called to interview within two weeks of the child's seventh birthday, which has two advantages for evaluation purposes. First, to the best of our knowledge, the child's date of birth is recorded accurately for all recipients. Second, the timing of the 'treatment' - which we take as commencing on the child's seventh birthday - is determined solely by the child's age. A similar proportion of this particular group signed Activity Agreements, and with similar timing relative to the interview date, as for the wider group. ${ }^{12}$

Before moving on, it is worth briefly setting out some additional details on payment rates and taper rates for those with other income, since these may differ from welfare payments to low-income parents in other countries. There are also differences in these characteristics between PPS and PPP which may help to explain any differences in the impacts of the reforms by payment type. These were not changed as part of the 2006 or 2007 reforms, although they have been periodically updated since. The figures given below refer to fortnightly periods and are those in place as of March 2011. The maximum PPS payment, for those earning no more than $\$ 170.60$ (plus $\$ 24.60$ for each additional child), is $\$ 611.90$. Payments are reduced by 40 cents in the dollar for those earning above this threshold, with parents no longer eligible for part payments once their income exceeds $\$ 1,673.85$ (again plus $\$ 24.60$ for each additional child). In contrast, the maximum PPP payment is $\$ 424.00$. Eligibility for the maximum payment is dependent on whether the individual's partner also receives a pension (e.g. PPP or other IS pension, Age Pension). If this is the case, then combined income must be less than \$124 for maximum payment, with taper rates for combined income above this threshold initially 25 cents in the dollar (up to \$500) and then 30 cents in the dollar, up to a maximum combined income of $\$ 1,579$. If the partner does not receive a pension, then own income must be less than $\$ 62$ and partner's income less than $\$ 790$ for maximum payment. Taper rates are 60 cents in the dollar for own income (50 cents below $\$ 250$ ) and partner's income, up to a maximum of $\$ 789.50$ (own income), and $\$ 1,486.17$ (partner's income) and \$1,589.50 (combined income). In summary, PPS payments are higher than PPP payments at all eligible income levels for those whose partners receive a pension, although PPP taper rates are lower. For those whose partners do not receive a pension, PPP can be more generous than PPS for partners earning less than $\$ 1,100$, but taper rates are higher.

\section{Existing evaluations of related reforms}

Most welfare to work reforms in most countries set out with the aims of reducing welfare caseloads and boosting labour force participation, whether for lone or low-income parents, for the long-term unemployed or for other groups of welfare recipients. Typically, these reforms consist of increased activity requirements (e.g. compulsory job search or training, with sanctions for those that are not sufficiently active) and provision of 
additional or improved employment-related assistance (e.g. with job search, training or child care). ${ }^{13}$ Grogger and Karoly (2005) show how these kinds of reforms can be expected to increase incentives to work in a simple static model of labour supply. Others have used search models to show similar incentive effects (e.g. Johnson and Klepinger, 1994; Fredriksson and Holmlund, 2005; Manning, 2009).

The international empirical evidence suggests that different measures work to different extents for different groups and in different contexts, with exit from a particular payment not necessarily synonymous with welfare exit, and welfare exit not necessarily synonymous with labour force participation. For general cross-country reviews see Heckman et al. (1999), Martin and Grubb (2001) and Carcillo and Grubb (2006). For reviews of welfare to work reforms specifically for low-income parents see Blank (2002), Grogger and Karoly (2005), and Moffitt (2008) for the US, and Finn and Gloster (2010) across countries (including earlier Australian reforms).

Here we briefly discuss the evidence from the 1990s US welfare reforms- associated with the replacement of Aid to Families with Dependent Children (AFDC) with Temporary Assistance for Needy Families (TANF) in 1996, and the preceding period of state-level experimentation with different approaches to welfare under the waiver system - in part because they have been extensively evaluated, but also because some of the key characteristics of these reforms at both the Federal and state level were similar to the Australian welfare to work reforms of interest here. TANF is a Federal program, which among other things, mandates participation in work or work-related activities of up to 30 hours per week, after an initial period, for lone parents whose youngest child is six years or older (although with some exemptions). Individual states have had considerable discretion in the timing and nature of its implementation and the resulting variation in the program along with the preceding period of state-level waivers, is one reason for the extensive evaluation literature on the US reforms over this period.

The weight of evidence from this body of evaluation studies, using a variety of methods and data sources, points to significant caseload-reduction impacts from the introduction of TANF (through both increased exits and reduced entry ${ }^{14}$ ), significant positive impacts on job entry for those exiting welfare and on employment for the target group overall, and significant increases in participation in paid work for those remaining on welfare. In terms of particular reform components, according to Grogger and Karoly (2005) there were more studies of mandatory activity requirements - the aspect of the reforms that is closest to the Australian reforms - than any other type of reform. (There were also more studies of impacts on welfare use - the outcome we study in this paper - than on any other outcome variable). In terms of magnitude, experiment-based estimates of the decline in welfare rolls as a result of the mandatory participation requirements introduced under the state-level waivers suggest an average reduction of 5.1 percentage points over two years (Grogger and Karoly, 2005). We keep this estimate in mind when interpreting the magnitude of the impacts of the Australian welfare reform on caseload, although we stop short of drawing conclusions regarding direct comparisons of magnitudes.

One reason why we might expect different impacts of welfare reforms introducing mandatory activity requirements in Australia compared to the US is that labour force participation among mothers of young children is comparatively low in Australia. Bergemann and van den Berg (2008) argue that ALMP impacts for women may be 
higher in labour markets with low female participation rates because such labour markets may imply higher wage elasticity and because they imply female welfare recipients who are more highly skilled on average. They present evidence that suggests such a pattern in the magnitude of ALMP impacts for women may exist. Australia's high minimum wages (and other labour market rigidities) might act against this, however, by constraining labour demand for low-skilled workers among this group of welfare recipients, with any off-setting impact on labour supply itself constrained by the high marginal tax rates facing those on PP.

The potential availability of other welfare payments, and the relative ease with which one can switch between payments, may also be an important point of difference between Australia and the US for this group. Mandatory activity requirements for one type of payment are likely to reduce the utility of welfare recipients on that payment, at least in the short run, and a rational response would be to try to avoid these requirements by switching to alternative payments where possible. So exit from PP may not always correspond with exit from welfare altogether or entry to the labour market. Evidence that reforms to one particular welfare benefit can lead to 'benefit shift' between payments is becoming increasingly common. For a recent example from a reform to UK unemployment benefits see Petrongolo (2009). ${ }^{15}$

What can we learn about the possible impacts of the 2007 reforms from evaluations of earlier Australian welfare reforms for low-income parents? An early small-scale pilot extension of the JET interview program has been the subject of a couple of studies, both finding evidence of statistically significant impacts on various outcomes (see Barrett and Cobb-Clark, 2000; Dockery and Stromback, 2004). Perhaps more useful for our particular purposes, however, is the in-house evaluation of the 2006 welfare to work reforms for low-income parents by the relevant government department (DEEWR, 2008). In the absence of random experimental evidence, the DEEWR study adopts a combination of before and after comparisons and unconditional difference-in-differences (comparing changes in means) - with identification based on age of youngest child - to estimate the impacts of introducing the package of activation measures for new claimant low-income parents, as described in Section 2, on a variety of outcomes. The resulting evidence suggests that for those low-income parents whose youngest child was school aged, the 2006 reforms reduced inflows to IS, increased transfers from PP to other non-activity tested IS payments such as Disability Support Pension (DSP), increased participation in employment services, decreased the duration on $\mathrm{IS}^{16}$, and, at least for partnered parents or single parents with a youngest child aged six or seven years, increased participation in paid employment for those still on IS.

\section{Data and preliminary estimates}

The RED records all episodes of IS receipt, along with details required to administer payment (e.g. earnings from paid employment) and some others, from the late 1990s onwards. It is longitudinal in the sense that individuals are tracked across multiple episodes, although it contains no information on individuals for periods outside of IS. Its main advantages are that it contains information on the full population of PP recipients, is continuous in time (IS 'events' are recorded to the day) and that data are reported accurately at least for information required to administer payments. Its main 
disadvantages are the lack of information outside of IS episodes and lack of detail and potential unreliability of information that is not required to administer IS payment. Specifically, we know nothing about labour force participation once off welfare, and although we do observe some information on hours of paid work while on welfare, such data are only reliable following activation (when they are required for administration of the welfare payment). This limits the outcomes we can study here to welfare exit and switching between welfare payments.

Because of its size and complexity we take a ten percent random sample of the relevant RED population - all grandfathered PP recipients as of $30^{\text {th }}$ June 2006 - and track them for all IS episodes from the beginning of the episode which was ongoing on $30^{\text {th }}$ June 2006 until $30^{\text {th }}$ June 2009. This gives us information on 90,664 IS episodes covering 59,490 individuals. By $30^{\text {th }}$ June 2009 the stock of recipients from this ten percent sample that were still receiving PP was down to just over 30,000 individuals, with some no longer receiving IS and others receiving other IS payments. Note that, by definition, there are no inflows to the grandfathered cohort beyond 30 June 2006, only outflows. Over the same period the total number of PP recipients - including new entrants to PP outside of the grandfathered group - fell by around twenty percent (see Figure 1).

For each IS episode we have (time-varying) data on type of benefit claimed, episode start and end dates (right-censored if ongoing), benefit history of the individual, number of children and age of youngest child, age of the recipient parent, country of birth of the recipient parent, the Labour Force Statistical Region (LFSR) for each individual with which we assign local unemployment rates to individuals, along with information on the date of the initial activation interview with the Centrelink advisor (for those activated) and the signing date for any subsequent (compulsory) Activity Agreement. We treat these episodic data as continuous in time and use them to analyse the duration of PP episodes and to estimate hazard functions for the daily probabilities of exiting PP, exiting PP to other IS payments and exiting IS.

Table 1 presents summary information for our grandfathered sample, separately by benefit type. The mean duration of a completed PP episode is 1716 days, i.e. between four and five years, but many episodes - around 40\% - are still ongoing at the last point of observation ( $30^{\text {th }}$ June 2009), so that these mean completed episode durations understate the mean duration of all PP episodes for the grandfathered cohort. PPS

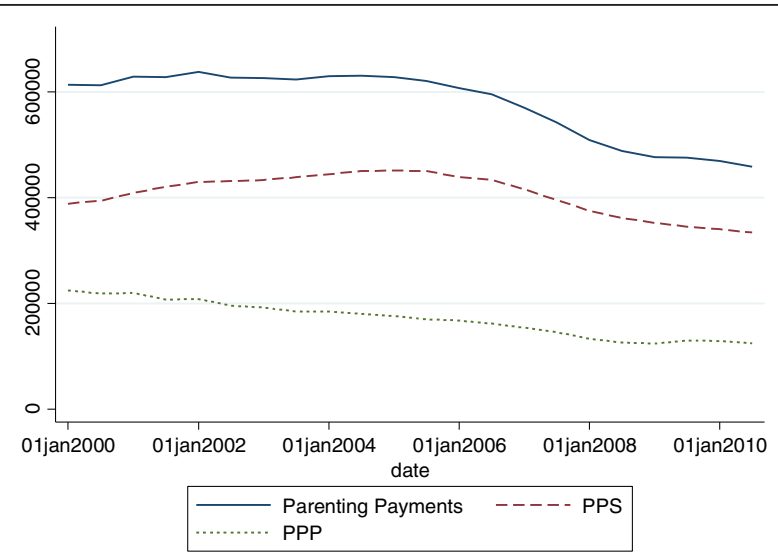

Figure 1 Number of PP recipients, Jan 2000 - July 2010. 
Table 1 Durations and covariate sample means (Standard Deviations), full sample

\begin{tabular}{lccc}
\hline & All PP & PPS & PPP \\
\hline Completed PP episode duration, days & $1716(1156)$ & $1870(1149)$ & $1392(1104)$ \\
Episode duration including right-censored episodes & $2019(1172)$ & $2157(1144)$ & $1649(1169)$ \\
Elapsed duration in current episode to 30 June 2006, days & $1218(1035)$ & $1343(1039)$ & $954(975)$ \\
Male & .101 & .096 & .110 \\
Age of parent & $36.7(9.24)$ & $36.9(9.26)$ & $36.0(9.18)$ \\
Immigrant & .264 & .215 & .369 \\
Number of children <16 & $1.67(.927)$ & $1.55(.823)$ & $1.94(1.07)$ \\
LFSR Unemployment Rate, \% & $4.85(1.31)$ & $4.80(1.31)$ & $4.97(1.31)$ \\
Previous IS episodes duration (prior to current episode), years & $3.96(3.56)$ & $4.03(3.58)$ & $3.80(3.52)$ \\
Proportion of episodes ending within window & $62.9 \%$ & $58.4 \%$ & $74.8 \%$ \\
\hline
\end{tabular}

Note: covariates are measured at end episode or right-censoring date.

episodes are longer on average than PPP episodes. By definition no episodes can end before 30 June 2006 - either the individual concerned would not be in the grandfathered group or the episode ending prior to 30 June 2006 would be excluded from the sampling frame - but we have information on the elapsed duration of the current episode prior to this cut-off date, which again tends to be higher for PPS recipients compared to PPP recipients. We also have information on previous IS episodes, which on average sum to four years duration across both benefit types. Around $90 \%$ of grandfathered PP recipients are women. The average age of grandfathered PP recipients is around 36 years. Around one quarter of grandfathered PP recipients were born outside of Australia. Grandfathered PP recipients have an average of two children under 16 and they face an average local unemployment rate of around 5\%.

Before turning to discussion of the hazard models we take a first pass at the data by presenting simple unconditional difference-in-differences estimates that compare mean outcomes before and after the 2007 reforms for those covered by the new requirements (i.e. with a youngest child aged seven years or older) and for those not covered by the new requirements (i.e. those with a youngest child aged under seven years). This kind of ageof-youngest-child based approach to identification is common in the non-experimental evaluation literature on welfare reforms for low-income parents (e.g. Grogger and Michalopoulos, 2003; Grogger, 2004; Cebulla et al., 2008), and was adopted by the DEEWR (2008) study of the earlier 2006 Australian reforms. For simplicity we treat the period prior to $1^{\text {st }}$ July 2007 as pre-activation and the period from $1^{\text {st }}$ July 2007 as postactivation (i.e. we initially ignore the phasing in of activation).

Tables 2, 3 and 4 give the relevant mean durations of completed episodes. Note that because of the way the sample is constructed, episodes ending after $1^{\text {st }}$ July 2007 are, by definition, longer on average than those ending prior to $1^{\text {st }}$ July 2007, both for those with a youngest child under seven and those with a youngest child aged seven or older. But by comparing the change in mean durations of completed episodes, before and after $1^{\text {st }}$ July 2007 for the two age groups, we can get a simple unconditional difference-in-differences estimate of the impact of activation on completed PP episode duration. From Table 2 we can see that the average duration of PP episodes completed after $1^{\text {st }}$ July 2007 for those with youngest child under seven is $86 \%$ longer than those completed prior to $1^{\text {st }}$ July 2007; whereas for those with youngest child aged seven or 
Table 2 Mean durations (Standard Deviations) and exit rates, all PP, before and after $1^{\text {st }}$ July 2007 by age of youngest child

\begin{tabular}{|c|c|c|c|c|}
\hline & $\begin{array}{l}\text { Child under } 7 \text { at end } \\
\text { of episode, episode, } \\
\text { ends before } \\
1^{\text {st }} \text { July } 2007\end{array}$ & $\begin{array}{l}\text { Child 7+ at end of } \\
\text { episode, episode } \\
\text { ends before } \\
1^{\text {st } J u l y ~} 2007\end{array}$ & $\begin{array}{l}\text { Child under } 7 \text { at end } \\
\text { of episode, episode } \\
\text { ends after } \\
30^{\text {th }} \text { June } 2007\end{array}$ & $\begin{array}{l}\text { Child } 7+\text { at end of } \\
\text { episode, episode } \\
\text { ends after } \\
30^{\text {th }} \text { June } 2007\end{array}$ \\
\hline $\begin{array}{l}\text { Completed PP } \\
\text { episode } \\
\text { duration, days }\end{array}$ & 834 (723) & 1568 (1118) & $1554(815)$ & 2436 (1117) \\
\hline $\begin{array}{l}\text { Episode } \\
\text { duration } \\
\text { including } \\
\text { right-censored } \\
\text { episodes }\end{array}$ & 722 (954) & 1171 (1369) & $1310(1058)$ & 1709 (1414) \\
\hline $\begin{array}{l}\text { Proportion of } \\
\text { episodes } \\
\text { ending within } \\
\text { window }\end{array}$ & $13.9 \%$ & $13.3 \%$ & $12.9 \%$ & $22.7 \%$ \\
\hline
\end{tabular}

Notes: Episode durations refer to complete episodes only and are measured in days. 'Episode duration including rightcensored episodes' for the period up to $1^{\text {st }}$ July 2007 takes this date as the right-censoring date. The denominator for 'proportion of episodes ending within window' is the total number of episodes.

older it is 55\%. The corresponding unconditional difference-in-differences estimate is therefore that activation has led to or has coincided with a reduction in mean duration of completed PP episodes, for those covered by the new requirements, of $31 \%$. The corresponding unconditional difference-in-differences estimates for PPS and PPP recipients are a reduction of $15 \%$ in mean PPS episode duration (see Table 3) and a reduction of $49 \%$ in mean PPP episode duration (see Table 4). A similar unconditional difference-in-differences estimate of the impact of activation on episode duration including right-censored episodes, where the right-censoring date is treated as the end date, suggests duration falls by $36 \%$ for those covered by the new participation requirements. The equivalent figures for PPS and PPP durations are falls of $34 \%$ and $65 \%$ respectively.

Tables 2, 3 and 4 also report the fraction of episodes that end before and after $30^{\text {th }}$ June 2007 for each of the age-of-youngest-child groups. We can use this information in similar fashion to obtain rough, unconditional, difference-in-differences

Table 3 Mean durations (Standard Deviations) and exit rates, PPS only, before and after $1^{\text {st }}$ July 2007 by age of youngest child

\begin{tabular}{|c|c|c|c|c|}
\hline & $\begin{array}{l}\text { Child under } 7 \text { at end } \\
\text { of episode, episode } \\
\text { ends before } \\
1^{\text {st July } 2007}\end{array}$ & $\begin{array}{l}\text { Child } 7+\text { at end of } \\
\text { episode, episode } \\
\text { ends before } \\
1^{\text {st } J u l y ~} 2007\end{array}$ & $\begin{array}{l}\text { Child under } 7 \text { at end } \\
\text { of episode, episode } \\
\text { ends after } \\
30^{\text {th }} \text { June } 2007\end{array}$ & $\begin{array}{l}\text { Child } 7+\text { at end of } \\
\text { episode, episode } \\
\text { ends after } \\
30^{\text {th }} \text { June } 2007\end{array}$ \\
\hline $\begin{array}{l}\text { Completed PP } \\
\text { episode } \\
\text { duration, days }\end{array}$ & $983(760)$ & 1665 (1102) & $1610(829)$ & 2485 (1101) \\
\hline $\begin{array}{l}\text { Episode } \\
\text { duration } \\
\text { including } \\
\text { right-censored } \\
\text { episodes }\end{array}$ & 901 (986) & 1897 (1123) & 1515 (1061) & 2547 (1155) \\
\hline $\begin{array}{l}\text { Proportion of } \\
\text { episodes } \\
\text { ending within } \\
\text { window }\end{array}$ & $10.3 \%$ & $13.3 \%$ & $10.8 \%$ & $23.9 \%$ \\
\hline
\end{tabular}

Notes: Episode durations refer to complete episodes only and are measured in days. 'Episode duration including rightcensored episodes' for the period up to $1^{\text {st }}$ July 2007 takes this date as the right-censoring date. The denominator for 'proportion of episodes ending within window' is the total number of episodes. 
Table 4 Mean durations (Standard Deviations) and exit rates, PPP only, before and after $1^{\text {st }}$ July 2007 by age of youngest child

\begin{tabular}{lcccc}
\hline & $\begin{array}{c}\text { Child under } \mathbf{7} \text { at end } \\
\text { of episode, episode } \\
\text { ends before } \\
\mathbf{1}^{\text {st }} \text { July } \mathbf{2 0 0 7}\end{array}$ & $\begin{array}{c}\text { Child 7+ at end of } \\
\text { episode, episode } \\
\text { ends before } \\
\mathbf{1}^{\text {st }} \text { July } \mathbf{2 0 0 7}\end{array}$ & $\begin{array}{c}\text { Child under } \mathbf{7} \text { at end } \\
\text { of episode, episode } \\
\text { ends after } \\
\mathbf{3 0}^{\text {th }} \text { June 2007 }\end{array}$ & $\begin{array}{c}\text { Child 7+ at end of } \\
\text { episode, episode } \\
\text { ends after } \\
\mathbf{3 0}^{\text {th }} \text { June 2007 }\end{array}$ \\
\hline $\begin{array}{l}\text { Completed PP } \\
\text { episode } \\
\text { duration, days }\end{array}$ & $658(633)$ & $1305(1110)$ & $1465(786)$ & $2274(1155)$ \\
$\begin{array}{l}\text { Episode } \\
\text { duration } \\
\text { including } \\
\text { right-censored } \\
\text { episodes }\end{array}$ & $505(852)$ & $1706(1190)$ & $1032(977)$ & $2379(1243)$ \\
$\begin{array}{l}\text { Proportion of } \\
\text { episodes } \\
\text { ending within } \\
\text { window }\end{array}$ & $23.6 \%$ & $13.3 \%$ & & \\
\hline
\end{tabular}

Notes: Episode durations refer to complete episodes only and are measured in days. 'Episode duration including rightcensored episodes' for the period up to $1^{\text {st }}$ July 2007 takes this date as the right-censoring date. The denominator for 'proportion of episodes ending within window' is the total number of episodes.

estimates of the impact of activation on the probability of completing an episode by a certain date. In this case the suggestion is that activation led to or coincided with an increase in the proportion of episodes ending beyond $30^{\text {th }}$ June 2007 but prior to $30^{\text {th }}$ June 2009 of 9.4 percentage points for the treatment group, with a corresponding fall of one percentage point for the comparison group, suggesting a difference-in-differences estimate of a 10.4 percentage point increase in the proportion of episodes ending within the period. The corresponding difference-in-differences estimates for PPS and PPP are 10.1 percentage points and 11.2 percentage points.

Figure 2 presents Kaplan-Meier (KM) hazard functions ${ }^{17}$ before and after 'activation', separately for PPS and PPP recipients and by age group of youngest child, first for exits to other IS payments and then for exits from IS altogether. Hazards for exit from both PPS and PPP to other IS payments have increased for the grandfathered cohort following $1^{\text {st }}$ July 2007 whether the youngest child is aged seven or older or aged under seven, but the increase in the hazard for those with older children is noticeably larger than the increase in the hazard for those with younger children. For PPP recipients the increase in the KM hazard for those with youngest child aged seven or older is particularly pronounced. There is a similar picture for exits from IS, again with the impact on PPP recipients particularly pronounced. Note that such exits are more common than exits to other IS payments both before and after activation.

On balance the suggestion from both the simple unconditional difference-in-differences estimates and the KM hazard plots is that the 2007 reforms coincided with a relative increase in the hazard rate for exiting PP for those covered by the new requirements, both to other IS payments and exiting IS altogether, and for both PPS and PPP recipients. The result is shorter PP episode durations and fewer ongoing episodes relative to those not covered by the new requirements. ${ }^{18}$ Activation also appears to have coincided with a larger relative increase in the hazard rate for covered PPP recipients compared to covered PPS recipients (we return to this point later). In the following section we extend this ageof-youngest based approach to try to better pin down the causal impact of activation on outcomes in a proportional hazard model framework. 


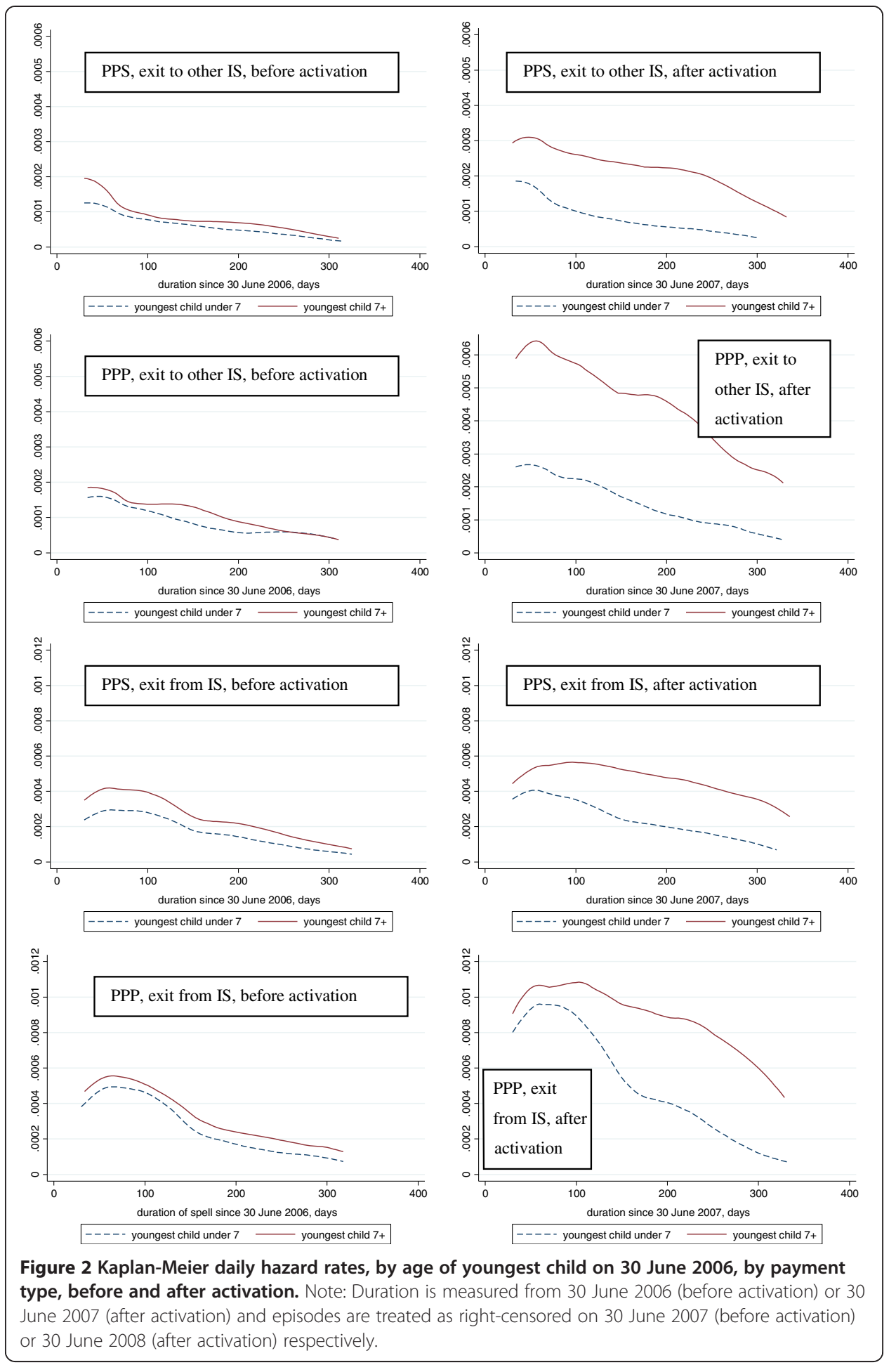

\section{Econometric model and identification}

We require that the probability of being treated is independent of outcomes, conditional on observed characteristics and other control variables. One potential problem related to the non-random phasing-in of the participation requirements for PP recipients with a child already aged seven years or older as of $1^{\text {st }}$ July 2007 - with those 
deemed furthest from the labour market treated up to one year earlier than those deemed closer to the labour market - is that those with unobserved characteristics associated with higher hazard rates are less likely to survive until treatment compared to those with less favourable characteristics. There are also reasons to be concerned about missing values and inaccuracies in the recording of activation interview dates in the data. We therefore restrict the sample to focus on those in the grandfathered group with a youngest child aged under seven as of $1^{\text {st }}$ July 2007, but who then subsequently turned seven during the following year. In other words we focus on parents on PP with a youngest child aged six years old on $1^{\text {st }}$ July 2007. Parents in this category were called to interview within two weeks of the child's seventh birthday, which is measured accurately. Our treatment variable is therefore equal to zero for the period prior to the child's seventh birthday and equal to one following the child's seventh birthday.

For a comparison group we take the equivalent cohort one year earlier, i.e. those grandfathered parents with a youngest child aged six years old on $1^{\text {st }}$ July 2006 . The youngest children of the parents in this group will turn seven during the subsequent year running up to $30^{\text {th }}$ June 2007 , but this will not trigger activation because of the grace period for grandfathered parents. Individuals are assumed to be at risk of exit from the $30^{\text {th }}$ June 2006 (comparison group) or the $30^{\text {th }}$ June 2007 (treatment group), with ongoing episodes treated as right-censored as of $30^{\text {th }}$ June 2007 (comparison group) or $30^{\text {th }}$ June 2008 (treatment group).

Our outcomes of interest are the single risk hazard rate for exit from PP (including exit to other IS payments) and competing risk hazard rates for exits from PP to other IS benefits and exits from PP off IS altogether. ${ }^{19}$ We take a reduced form Cox Proportional Hazards (CPH) approach to estimation (see van den Berg, 2001) as given below:

$$
\begin{aligned}
h(t)=h_{0}(t) \exp (\alpha D & +\beta_{1} x_{1}+\ldots+\beta_{N} x_{N}+\gamma_{1} \text { treatmentgroup } \\
& \left.+\gamma_{2} \text { turned } 7+\delta \text { turned } 7 * \text { treatmentgroup }\right)
\end{aligned}
$$

In (1), $h(t)$ is the hazard rate for the relevant outcome, $h_{0}(t)$ is the baseline hazard, $D$ is elapsed duration in the current episode prior to $30^{\text {th }} J$ une 2006 (for the comparison group) or $30^{\text {th }}$ June 2007 (for the treatment group), $x_{1} \ldots x_{N}$ are observed individual characteristics of the parent, e.g. gender, number of children, and whether born outside Australia, treatmentgroup is a binary dummy indicating whether the individual is in the treatment group (those with a six year old child on $1^{\text {st }}$ July 2007), and turned 7 is a binary dummy equal to zero for parents with a youngest child aged six and equal to one with a youngest child aged seven. We interpret the interaction of these last two terms as the treatment indicator, withour estimate of the treatment effect therefore given by $\hat{\delta}$.

Specified in this way, the treatmentgroup dummy controls for differences in (observed and unobserved) characteristics between the treatment and control groups (which in any case look similar in terms of observed characteristics), and the turned7 dummy controls for any differences in PP claiming associated with the child turning seven that are not related to activation (which in any case are likely to be small because all six and seven year olds are required to attend school throughout Australia). Differential trends over the oneyear periods in question for these two groups can be plausibly ruled out given their high degree of similarity. It's also difficult to think of any plausible candidate for an empirically important asymmetric shock during these one-year periods. For example, the labour 
market impacts of the global financial crisis, which in any case were more muted in Australia than in many other OECD countries, were not felt until late 2008/early 2009, after the period of interest here.

Even in the absence of phasing in of treatment for this restricted sample, however, it is still possible for PP recipients in either the comparison or treatment groups to exit PP before their youngest child turns seven. In other words those still on PP when their youngest child turns seven may form a select group. But because we are looking at a relatively short window (most individuals in both groups survive until this point) and because the groups are observationally so similar, this is unlikely to impart a large selection bias. Our results are also robust to adding a (gamma-distributed) unobserved heterogeneity term to (1). ${ }^{20}$

All told we believe we have a compelling identification strategy, at least compared to many of the non-experimental estimates of the impacts of the 1990s US reforms. ${ }^{21}$ Having said that, our estimates are for rather narrowly drawn outcomes, and for a relatively narrow group of parents (although arguably the most interesting group), so we trade-off a high degree of internal validity for potentially lower external validity. ${ }^{22}$

\section{Estimated impacts of activation on hazard rates}

First consider the single risk hazard model for exits from PP presented in Table 5. Controls generally take expected signs (e.g. see Gregory and Klug, 2003; Gong, 2004), although coefficients are not always statistically significant: males have higher hazards; older parents have marginally lower hazards for PPS; immigrant PPP recipients have lower hazards; PPS recipients with more children have lower hazards; and the unemployment rate is negatively related to the hazard. Elapsed duration in the current episode prior to being at risk is negatively related to the hazard, consistent with the standard finding of a downward sloping hazard function for welfare exit. Hazards are also lower for those in the treatment group, given activation status, capturing differences in characteristics between the two groups not otherwise controlled for. The zero coefficients on the dummy for youngest child turning seven, both here and in the competing risks estimates, can be interpreted as placebo tests: for those in the comparison group this has no impact on either the single risk hazard or the competing risks hazards.

Turning to the estimated treatment effects, when the model is estimated on all grandfathered PP recipients, the coefficient on the treatment dummy is large, positive and highly statistically significant, with the single risk hazard $64 \%$ higher following treatment than prior to treatment, other things being equal. As a consequence, over the first year of the new regime the caseload for those grandfathered parents with a youngest child aged 6 at the start of the year fell by 23.5\%;without activation it would have fallen by $18.5 \%$, i.e. a difference of 5 percentage points. ${ }^{23}$ If we extrapolate this estimated impact for two years and assume that everyone is treated on day 1 of the first year, then the estimated caseload for this group falls by $45 \%$ compared to an estimated $34 \%$ under the counterfactual, i.e. an additional drop of 11 percentage points.

So, like the earlier US reforms, the Australian reforms had large, positive, and statistically significant impacts on welfare exit. At first glance the caseload impact of these Australian reforms appears to be around twice as large as the average reduction in caseload attributed to the introduction of work requirements in the US reported by 
Table 5 Cox proportional hazard model, single risk (All Exits from PP), restricted sample, coefficients (Standard Errors)

\begin{tabular}{|c|c|c|c|}
\hline & $\begin{array}{l}\text { All Grandfathered } \\
\text { PP recipients }\end{array}$ & $\begin{array}{l}\text { Grandfathered } \\
\text { PPP recipients }\end{array}$ & $\begin{array}{l}\text { Grandfathered } \\
\text { PPS recipients }\end{array}$ \\
\hline \multirow[t]{2}{*}{ Activation } & $.639 * * *$ & $.882^{* * *}$ & $.511^{* * *}$ \\
\hline & $(.104)$ & $(.183)$ & $(.127)$ \\
\hline \multirow[t]{2}{*}{ Treatment group } & $-.232^{* * *}$ & -.195 & $-.204^{* *}$ \\
\hline & $(.075)$ & $(.134)$ & $(.091)$ \\
\hline \multirow[t]{2}{*}{ Youngest child 7 years old } & -.021 & -.034 & .003 \\
\hline & $(.076)$ & $(.131)$ & $(.093)$ \\
\hline \multirow[t]{2}{*}{ Male } & $.234^{* * *}$ & .135 & .144 \\
\hline & $(.083)$ & $(.127)$ & $(.111)$ \\
\hline \multirow[t]{2}{*}{ Age of parent } & $-.007^{*}$ & .006 & $-.017^{* * *}$ \\
\hline & $(.004)$ & $(.007)$ & $(.005)$ \\
\hline \multirow[t]{2}{*}{ Immigrant parent } & -.020 & $-390 * * *$ & -.026 \\
\hline & $(.060)$ & $(.097)$ & $(.079)$ \\
\hline \multirow[t]{2}{*}{ Number of children under 16 years } & .021 & .003 & $-.066^{*}$ \\
\hline & $(.026)$ & $(.040)$ & $(.037)$ \\
\hline \multirow[t]{2}{*}{ LFSR unemployment rate, \% } & $-.054^{* * *}$ & $-.079 * *$ & $-.053^{* *}$ \\
\hline & $(.020)$ & $(.036)$ & $(.024)$ \\
\hline \multirow[t]{2}{*}{ Past IS duration, years } & -.007 & -.007 & -.006 \\
\hline & $(.007)$ & $(.014)$ & $(.009)$ \\
\hline \multirow{2}{*}{$\begin{array}{l}\text { Elapsed duration of current episode prior to } 30 \\
\text { June } 2006 \text { (control group) and } 30 \text { June } 2007 \\
\text { (treatment group), years }\end{array}$} & $-.145^{* * *}$ & $-.140^{* * *}$ & $-.142^{* * *}$ \\
\hline & $(.011)$ & $(.018)$ & $(.014)$ \\
\hline No. Individuals & 6490 & 1486 & 5004 \\
\hline No. Failures & 1552 & 517 & 1035 \\
\hline Log (pseudo) likelihood & -13284 & -3603 & -8616 \\
\hline
\end{tabular}

Notes: ${ }^{* * *},{ }^{* *}$ and ${ }^{*}$ denote statistical significance at $99 \%, 95 \%$ and $90 \%$ respectively. The restricted sample combines those with a youngest child aged 6 years on the $30^{\text {th }}$ June 2006 (control group) and those with a youngest child aged 6 years on $30^{\text {th }}$ June 2007 (treatment group). Returners to PP after 30 June 2006 are omitted. The treatment group dummy is equal to 1 for those in the latter group and 0 for those in the former group. The youngest child aged 7 dummy is equal to one for those with a youngest child aged 7 years and 0 otherwise. Activation is a binary dummy equal to the product of the treatment group and youngest child aged 7 dummies. Age of parent is expressed in years. Past IS episode duration is expressed in years (since $1^{\text {st }}$ January 1998) as is elapsed duration of current episode. Results are presented in coefficient form, i.e. the $\beta s, y s$ and $\delta$ s from Equation (1), and are interpretable as semi-elasticities. Robust standard errors in parentheses.

Grogger and Karoly (2005). But there are several important caveats to note which make any such comparison of magnitudes difficult to interpret. First, this is an estimate of a local average treatment effect for a particular group of existing claimants. Second, we have assumed no re-entry (given that grandfathered status is lost on exit). Third, it is not straightforward to compare the 'toughness' of the Australian participation requirement to the average toughness of such requirements in the US covered by the experimental studies cited by Grogger and Karoly (2005).

Estimating the model separately on PPS and PPP recipients suggests the positive impact is common to both payment types, although the impact of activation appears to belarger for PPP recipients (the hazard increases by $88 \%$ ) compared to PPS recipients (the hazard increases by 51\%). PPP recipients may respond more strongly to activation than PPS recipients for a number of reasons. First, working 15 hours per week in paid employment is more likely to render a PPP recipient ineligible for PP on income 
grounds than is the case for PPS recipients. Second, although increased participation requirements may make PP less attractive for both PPS and PPP recipients - we can think of this as a harassment effect -PPPrecipients may be better able to compensate at a household level for lost PP income (if they exit) by increasing partner income, e.g. through increased earnings. ${ }^{24}$ There may also be compositional differences between PPS and PPP recipients in terms of unobservables - we know from Table 1 that there are differences in observables between the two groups - which could drive differences between the groups in the average impact of activation, although this could work in either direction.

Now consider the competing risks estimates for leaving PP for another IS payment presented in Table $6 .{ }^{25}$ Few characteristics controls are statistically significant, but where they are they generally take signs as we would expect: males (PPS recipients only), immigrants, those with more children under 16 and those with more previous time in receipt of IS prior to the current spell all have higher hazards for switching between payments, other things being equal. Elapsed duration in the current episode has a marginally significant negative impact on the hazard for exit to other IS payments, but of much smaller magnitude than in the single risk case. Again the treatment group dummy takes a negative sign and the dummy for youngest child turning 7 has no impact on the hazard.

Turning to the estimated treatment effects, for both PPS and PPP recipients there is a large, positive and highly statistically significant impact of activation on the hazard for exit to other IS payments, with the hazard more than doubling in each case. In other words, consistent with earlier evidence for Australia (e.g. DEEWR, 2008) and elsewhere (e.g. Petrongolo, 2009), tightening the conditionality of PP in 2007 had a significant impact in terms of displacement onto other IS payments. This may partly reflect the 'hard-to-help' nature of this group, many of whom had been on IS for several years prior to activation. Of course those moving to NSA or other 'active' IS payments may subsequently be more likely to exit IS than would otherwise have been the case, but those moving to DSP and other less active payments may be less so, or may take longer to do so than they would have in the absence of the reforms. The net effect of these reform impacts may therefore be to increase IS dependency. Note that in this case the estimated treatment effects appear very similar in magnitude for PPP recipients and PPS recipients. The implication is that the apparent PPP-PPS gap in the single risk case is being driven by exits from IS rather than switches between IS payments.

Next consider exits from IS (Table 7). Again controls are either insignificant or take expected signs: males and younger parents have higher hazards; immigrants, those in high unemployment labour markets and those with more previous time in receipt of IS have lower hazards. Again, elapsed duration in the current spell has a large negative impact on the hazard, the treatment group dummy takes a negative sign, and the dummy for youngest child turning 7 has no impact.

The estimated treatment effects, for both PPS and PPP recipients, again suggest a large, positive and highly statistically significant impact of activation. So the 2007 reforms did shift low income parents off IS, at least in the short term. These impacts are smaller in proportional terms than the impacts on switches between IS payments, but because the baseline hazard for welfare switches is lower than that for exits from IS, exits to other IS payments only constitute just over one third of the overall impact on caseload. $^{26}$ The activation impact on exits from IS is again larger (more than double) 
Table 6 Cox proportional hazard model, exit to other IS, restricted sample, coefficients (Standard Errors)

\begin{tabular}{lccc}
\hline & $\begin{array}{c}\text { All Grandfathered } \\
\text { PP recipients }\end{array}$ & $\begin{array}{c}\text { Grandfathered } \\
\text { PPP recipients }\end{array}$ & $\begin{array}{c}\text { Grandfathered } \\
\text { PPS recipients }\end{array}$ \\
\hline Activation & $1.14^{* *}$ & $1.23^{* * *}$ & $1.07^{* * *}$ \\
Treatment group & $(.223)$ & $(.362)$ & $(.282)$ \\
& $-.489^{* * *}$ & $-.473^{*}$ & $-.446^{* *}$ \\
Youngest child 7 years old & $(.171)$ & $(.285)$ & $(.217)$ \\
& -.057 & -.064 & -.027 \\
Male & $(.163)$ & $(.261)$ & $(.210)$ \\
Age of parent & .231 & -.208 & $.386^{*}$ \\
Immigrant parent & $(.174)$ & $(.283)$ & $(.218)$ \\
Number of children under 16 years & .004 & .007 & -.004 \\
Elapsed duration of current episode prior to 30 & $(.010)$ & $(.017)$ & $(.013)$ \\
June 2006 (control group) and 30 June 2007 & $.252^{* *}$ & .049 & .061 \\
(treatment group), years & $(.120)$ & $(.183)$ & $(.175)$ \\
No. Individuals & $.098^{*}$ & -.047 & .083 \\
No. Failures & $(.054)$ & $. .083)$ & $(.078)$ \\
Log (pseudo)likelihood & .050 & .046 & .027 \\
\hline
\end{tabular}

Notes: ${ }^{* * *},{ }^{* *}$ and ${ }^{*}$ denote statistical significance at $99 \%, 95 \%$ and $90 \%$ respectively. The restricted sample combines those with a youngest child aged 6 years on the $30^{\text {th }}$ June 2006 (control group) and those with a youngest child aged 6 years on $30^{\text {th }}$ June 2007 (treatment group). Returners to PP after 30 June 2006 are omitted. The treatment group dummy is equal to 1 for those in the latter group and 0 for those in the former group. The youngest child aged 7 dummy is equal to one for those with a youngest child aged 7 years and 0 otherwise. Activation is a binary dummy equal to the product of the treatment group and youngest child aged 7 dummies. Age of parent is expressed in years. Past IS episode duration is expressed in years (since $1^{\text {st }}$ January 1998) as is elapsed duration of current episode. Results are presented in coefficient form, i.e. the $\beta s, y s$ and $\delta$ s from Equation (1), and are interpretable as semi-elasticities. Robust standard errors in parentheses.

for PPP recipients than for PPS recipients, likely to reflect some combination of tighter income tests for PPP recipients, better 'outside options' for PPP recipients and compositional differences between the two groups.

Finally, anticipation effects - in the spirit of Black et al. (2003) - for those whose youngest child is aged six after 1st July 2007, could impart bias. We test robustness to this by including a dummy for the youngest child being between 6 years and 9 months and 7 years old, together with the interaction between this dummy and the treatment group dummy, with the latter intended to capture anticipation effects. The estimated treatment effects from this augmented model are presented in Table 8. In all cases the anticipation term is statistically insignificant, suggesting that parents are not exiting PP in anticipation of activation. The estimated treatment effects are also generally robust to this extension (slightly larger in the case of exits to other IS payments and slightly smaller in the case of exits from IS). 
Table 7 Cox proportional hazard model, exit from IS, restricted sample, coefficients (Standard Errors)

\begin{tabular}{|c|c|c|c|}
\hline & $\begin{array}{l}\text { All Grandfathered } \\
\text { PP recipients }\end{array}$ & $\begin{array}{l}\text { Grandfathered } \\
\text { PPP recipients }\end{array}$ & $\begin{array}{l}\text { Grandfathered } \\
\text { PPS recipients }\end{array}$ \\
\hline \multirow[t]{2}{*}{ Activation } & $.482^{* * *}$ & $.758^{* * *}$ & $.346^{* *}$ \\
\hline & $(.118)$ & $(.213)$ & $(.143)$ \\
\hline \multirow[t]{2}{*}{ Treatment group } & $-.166^{* *}$ & -.095 & -.151 \\
\hline & $(.083)$ & $(.152)$ & $(.100)$ \\
\hline \multirow[t]{2}{*}{ Youngest child 7 years old } & -.006 & -.017 & .015 \\
\hline & $(-.086)$ & $(.154)$ & $(.103)$ \\
\hline \multirow[t]{2}{*}{ Male } & $.243^{* * *}$ & .215 & .081 \\
\hline & $(.094)$ & $(.145)$ & $(.129)$ \\
\hline \multirow[t]{2}{*}{ Age of parent } & $-.012^{* * *}$ & .004 & $-.023^{* * *}$ \\
\hline & $(.005)$ & $(.08)$ & $(.006)$ \\
\hline \multirow[t]{2}{*}{ Immigrant parent } & -.103 & $-.551^{* * *}$ & -.052 \\
\hline & $(.068)$ & $(.115)$ & $(.088)$ \\
\hline \multirow[t]{2}{*}{ Number of children under 16 years } & -.001 & .019 & $-.110^{* * *}$ \\
\hline & $(.031)$ & $(.045)$ & $(.041)$ \\
\hline \multirow[t]{2}{*}{ LFSR unemployment rate, \% } & $-.084^{* * *}$ & $-.130^{* * *}$ & $-.073^{* * *}$ \\
\hline & $(.023)$ & $(.043)$ & $(.027)$ \\
\hline \multirow[t]{2}{*}{ Past IS duration, years } & $-.046^{* * *}$ & $-.049^{* * *}$ & $-.048^{* * *}$ \\
\hline & $(.008)$ & $(.016)$ & $(.010)$ \\
\hline \multirow{2}{*}{$\begin{array}{l}\text { Elapsed duration of current episode prior to } 30 \\
\text { June } 2006 \text { (control group) and } 30 \text { June } 2007 \\
\text { (treatment group), years }\end{array}$} & $-.173^{* * *}$ & $-.188^{* * *}$ & $-.170^{* * *}$ \\
\hline & $(.013)$ & $(.022)$ & $(.016)$ \\
\hline No. Individuals & 6490 & 1486 & 5004 \\
\hline No. Failures & 1194 & 381 & 813 \\
\hline Log (pseudo)likelihood & -10186 & -2633 & -6742 \\
\hline
\end{tabular}

Notes: ${ }^{* * *},{ }^{* *}$ and $*$ denote statistical significance at $99 \%, 95 \%$ and $90 \%$ respectively. The restricted sample combines those with a youngest child aged 6 years on the $30^{\text {th }}$ June 2006 (control group) and those with a youngest child aged 6 years on $30^{\text {th }}$ June 2007 (treatment group). Returners to PP after 30 June 2006 are omitted. The treatment group dummy is equal to 1 for those in the latter group and 0 for those in the former group. The youngest child aged 7 dummy is equal to one for those with a youngest child aged 7 years and 0 otherwise. Activation is a binary dummy equal to the product of the treatment group and youngest child aged 7 dummies. Age of parent is expressed in years. Past IS episode duration is expressed in years (since $1^{\text {st }}$ January 1998) as is elapsed duration of current episode. Results are presented in coefficient form, i.e. the $\beta \mathrm{s}, \gamma \mathrm{s}$ and $\delta \mathrm{s}$ from Equation (1), and are interpretable as semi-elasticities. Robust standard errors in parentheses.

Estimates are also robust to estimating on females only, to extending the sample to include those with youngest child aged 6 on $30^{\text {th }}$ June 2008 (censored at $30^{\text {th }}$ June 2009), and to inclusion in (1) of a (gamma-distributed) term for unobserved heterogeneity.

\section{Conclusions}

The evidence presented here shows that the welfare to work reforms for Australian low income parents introduced in 2007 led to an increase in exits from PP and a further reduction in PP caseload on top of that caused by the first round of reforms in 2006. Following activation, grandfathered low-income parents were more likely to exit PP, driven by increases in the hazards for both switching from PP to another IS payment and for exiting IS altogether. These estimated impacts are large in magnitude, suggesting that 
Table 8 Sensitivity to anticipation? Key coefficients (Standard Errors)

\begin{tabular}{lccc}
\hline & $\begin{array}{c}\text { All Grandfathered PP } \\
\text { recipients }\end{array}$ & $\begin{array}{c}\text { Grandfathered PPP } \\
\text { recipients }\end{array}$ & $\begin{array}{c}\text { Grandfathered PPS } \\
\text { recipients }\end{array}$ \\
\hline Standard Model & $.639^{* * *}$ & $.882^{* * *}$ & $.511^{* * *}$ \\
Single Risk (all exits & $(.104)$ & $(.183)$ & $(.127)$ \\
from PP) & $1.14^{* * *}$ & $1.23^{* * *}$ & $1.07^{* * *}$ \\
Exits to Other IS & $(.223)$ & $(.362)$ & $(.282)$ \\
Exits from IS & $.482^{* * *}$ & $.758^{* * *}$ & $.346^{* *}$ \\
Extended Model & $(.118)$ & $(.213)$ & $(.143)$ \\
Single Risk (all exits & $.508^{* * *}$ & & $.399^{* * *}$ \\
from PP) & $(.128)$ & $.663^{* * *}$ & $(.152)$ \\
Exits to Other IS & $1.65^{* * *}$ & $(.240)$ & $1.68^{* * *}$ \\
& $(.444)$ & $1.50^{*}$ & $(.531)$ \\
Exits from IS & $.516^{* * *}$ & $(.803)$ & $.410^{* *}$ \\
& $(.173)$ & $.624^{*}$ & $(.205)$ \\
\hline
\end{tabular}

Notes: $* * * * *$ and $*$ denote statistical significance at $99 \%, 95 \%$ and $90 \%$ respectively. The reported parameters are the coefficients and robust standard errors on the interaction of the treatment-group dummy and the turned7 dummy. The extended model includes an additional dummy equal to 1 for all those with a youngest child aged between 6 years and 9 months and 0 otherwise, and the interaction of this dummy with the treatment-group dummy, intended to control for anticipation effects in the three months prior to treatment. In all other respects the models are the same as those for Tables 5, 6 and 7 .

the caseload for this cohort of grandfathered parents fell by 5 percentage points more in the first year following the reforms than would have been the case under the counterfactual.

These kinds of reforms have not been extensively evaluated outside of the US. But the reforms share important characteristics with many of the state-level waivers and aspects of the TANF-related reforms introduced in the US in the 1990s, which have been extensively evaluated. Given these similarities, it perhaps comes as no surprise that we find similarly signed and statistically significant impacts (although direct comparisons of estimated magnitudes are difficult to interpret). Ex ante, however, this similarity in estimated impacts was by no means inevitable, given the differences between the Australian labour market and welfare system of 2007 and that of the US in the mid-1990s, and given we focus on a rather narrowly drawn group of parents here. One implication is that the impacts of such reforms may generalize reasonably well across countries and labour market contexts.

There is tentative evidence presented here that the impact of activation was larger for those in receipt of PPP (partnered parents) than for those in receipt of PPS (lone parents). This was driven by exits from IS rather than exits between IS payments, and may reflect tighter income restrictions for PPP eligibility and the opportunity, not open to PPS recipients, of responding to activation requirements - and the associated harassment factor - by exiting PP and compensating for the loss in household income by increasing partner earnings. Existing evaluations of welfare reforms for low income parents have tended to focus only on lone parents, presumably because few (or in some cases no) partnered parents are covered by the welfare payment under consideration (e.g. US TANF). 


\section{Endnotes}

${ }^{1}$ For a related review of European Active Labour Market Policy (ALMP) impacts on women see Bergemann and van den Berg (2008).

${ }^{2}$ For example, Indiana's IMPACT program introduced a work or related activity requirement of 20 hours per week (see Grogger and Karoly, 2005). The UK introduced similar requirements for lone parents with a youngest child aged seven years or older in 2010 (see Lane et al., 2011).

${ }^{3}$ For example, very few partnered parents were ever part of the AFDC program and payments to partnered parents were abolished with the introduction of TANF in 1996 (see Moffitt, 2008). Evaluations tend to focus on lone parents as a result.

${ }^{4}$ Centrelink is the agency that administers welfare payments and assigns welfare recipients to assistance programs in Australia.

${ }^{5}$ There is some variation across states in the school entry age, but all six year olds in all states are required to be in school.

${ }^{6}$ Activity Agreements are similar in nature to UK Jobseeker's Agreements (for more details see Manning, 2009).

${ }^{7}$ The 2011-12 Federal Budget announced an incremental reduction in this upper age limit but one that falls outside the period of our study.

${ }^{8}$ The existing requirement (since 2003) to attend an annual interview remained for those with a youngest child aged six.

${ }^{9} 75 \%$ of this group had been interviewed by the end of December 2007 and $99 \%$ by the end of June 2008. The first group of interviewees included those not engaged in any paid work and not registered with Job Network (the umbrella organization for providers of job search assistance and other employment services). The second group included those working less than 15 hours per week but not registered with Job Network or those registered with Job Network but not in paid work. Those in the third group - activated last - were already working 15 or more hours per week.

${ }^{10}$ 81.5\% of those that signed an Activity Agreement did so on the interview date. For the remainder, the mean gap between interview and signing an Activity Agreement was 93 days.

${ }^{11} 16 \%$ attended an interview but did not subsequently sign an Activity Agreement in the same PP episode.

${ }^{12}$ Grandfathered PP recipients whose youngest child is aged under seven have no participation requirements but may voluntarily access employment services.

${ }^{13}$ They may also be accompanied by measures to improve financial incentives to work, e.g. in-work tax credits or back to work bonuses.

${ }^{14}$ Moffitt (2008), p21 suggests that "a large fraction, if not the majority, arose from decreased entry to the program rather than increased exit".

${ }^{15}$ Also see Gregory and Klug (2003) for earlier Australian evidence on switches between welfare payments for low income parents.

${ }^{16}$ For example, they estimate that $23 \%$ of new PPS claimants with a youngest child aged 6-7 years had left IS after 6 months compared to $12 \%$ under the counterfactual. For those new claimants (re-)directed to NSA, the equivalent estimates were $38 \%$ versus $27 \%$ (lone parents) and $45 \%$ versus 32\% (partnered parents), i.e. a similar proportional increase for lone and partnered parents.

${ }^{17}$ KM hazards show the daily probability of exiting PP to a particular 'destination' given the parent has remained on PP until that day. Note that the daily hazards are very 
low - typically fewer than one in a thousand parents in receipt of PP on 30th June 2006 or 30th June 2007 exit on any given day subsequently - reflecting the long average duration of PP episodes (see Table 1).

${ }^{18}$ If anything these preliminary estimates may understate the impact of the reforms because they treat the implementation date as 1st July 2007 (for many it was later) and because some of those assigned to the comparison group on age of youngest grounds will themselves receive the 'treatment' when their youngest child turns seven.

${ }^{19}$ For tractability we assume independent competing risks.

${ }^{20}$ One model with unobserved heterogeneity fails to converge because of a flat likelihood function. We therefore present the estimates from the models not including unobserved heterogeneity, for which the full set are available.

${ }^{21}$ A common approach in this literature was to estimate state level panels with state and time fixed effects, with welfare reform packages captured by policy dummies. Blank (2002) sets out some of the potential problems with this approach, not least of which is the possibility that asymmetric state-level shocks or differential state-level trends may bias estimated treatment effects. Some studies in this literature adopted an identification strategy based on age of youngest child (e.g. Grogger, 2004), and in this respect are closer to our own strategy.

${ }^{22}$ For example, if treatment effects are heterogeneous by age of youngest child then our estimates may not generalize well for those with youngest child aged eight years or above.

${ }^{23}$ Assuming a uniform distribution of child birthdays throughout the year, on average individuals are treated from halfway through this first year.

${ }^{24}$ Although our data do not include information on labour force participation following exit from IS, it seems likely that at least some former PP recipients, and particularly former PPP recipients, move to non-claimant inactivity as a result of this harassment effect. (Manning 2009) suggests something similar happened in the UK as a result of reforms to unemployment benefits). The extent to which we might interpret this as a positive outcome of the reforms depends on the relative weights we give to the twin objectives of reducing benefit expenditures and increasing labour force participation.

${ }^{25}$ Such exits include switches to NSA, to DSP, and some switches from PPP to PPS. (Activated PPS recipients cannot switch to PPP because they would be treated as a new claimant and therefore re-directed to another payment, most likely NSA).

${ }^{26}$ The closest we can get to a comparison between the magnitude of this 'exits from IS' impact with that estimated by DEEWR (2008) for new claimant lone parents with youngest children aged 6-7 years is to compare the proportion of each group off IS after six months under the actual and counterfactual scenarios in each case. DEEWR (2008) suggest $23 \%$ of the new claimants had left IS after 6 months compared to $12 \%$ under the counterfactual. Our estimates suggest $12 \%$ of the grandfathered cohort had left IS after 6 months compared to $8 \%$ under the counterfactual. (Note that this assumes none of those that exit IS re-enter within the 6 months, so this is likely to overestimate the reduction in IS caseload). 


\section{Acknowledgements}

This paper is based on research commissioned by the Australian Government Department of Education, Employment and Workplace Relations (DEEWR) under the Social Policy Research Services Agreement (2010-2012) with the Melbourne Institute of Applied Economic and Social Research. Thanks to all those who offered useful advice during the course of the project. Thanks also to seminar participants at the Melbourne Institute and the 2012 Econometric Society Australasian Meeting for helpful comments. The views expressed are those of the authors alone and do not represent those of DEEWR or the Melbourne Institute.

Responsible editor: David Neumark.

Received: 06 December 2012 Accepted: 23 February 2013

Published: 19 April 2013

\section{References}

Banks M (2005) Parents, social security and the JET Active Labour Market Program in Australia: fitting the needs of the market or marketing the need to fit? Paper presented to Transitions and Risk: New Directions in Social Policy conference. University of Melbourne

Barrett GF, Cobb-Clark D (2000) The labour market plans of Parenting Payment recipients: information from a randomised social experiment. Australian J Labour Econ 4(3):192-205

Bergemann A, van den Berg G (2008) Active labor market policy effects for women in Europe: a survey. Annales d'Economieet de Statistique 91/92:377-399

Black DA, Smith JA, Berger MC, Noel BJ (2003) Is the threat of reemployment services more effective than the services themselves? Evidence from random assignment in the UI system. Am Econ Rev 93(4):1313-1327

Blank RM (2002) Evaluating welfare reform in the United States. J Econ Lit 40(4):1105-1166

Carcillo S, Grubb D (2006) From inactivity to work: the role of Active Labour Market Policies. OECD Social, Employment and Migration Working Papers No. 36. OECD, Paris

Cebulla A, Flore G, Greenberg D (2008) The New Deal for Lone Parents, lone parent Work Focused Interviews and Working Families Tax Credits: a review of impacts. Department for Work and Pensions Research Report No. 484, London

DEEWR (2008) Welfare to Work Evaluation Report. Department of Education, Employment and Workplace Relations, Canberra

Dockery AM, Stromback T (2004) An evaluation of a Parenting Payment intervention program. Australian J Soc Issues 39(4):431-442

Finn D, Gloster R (2010) Lone parent obligations: A review of recent evidence on the work-related requirements within the benefit systems of different countries. Department for Work and Pensions Research Report No. 632. HMSO, Norwich

Fredriksson P, Holmlund B (2005) Optimal unemployment insurance design: time limits, monitoring, or workfare? Institute for Labor Market Policy Evaluation Working Paper 2005:13

Gong X (2004) Transition patterns for the welfare reliance of low-income mothers in Australia. IZA Discussion Paper No. 1047. IZA, Bonn

Gregory RG, Klug E (2003) A picture book primer: welfare dependency and the dynamics of female lone parent spells. Australian National University, Canberra

Grogger J (2004) Time limits and welfare use. J Hum Resour 39(2):405-424

Grogger J, Michalopoulos C (2003) Welfare dynamics under time limits. J Polit Econ 111(3):530-554

Grogger J, Karoly LA (2005) Welfare Reform: Effects of a Decade of Change. Harvard University Press, Cambridge, MA

Heckman JJ, Lalonde RJ, Smith JA (1999) The Economics and Econometrics of Active Labour Market Programs. In: Ashenfelter O, Card D (eds) Handbook of Labour Economics Volume 3A. Elsevier, Amsterdam

Johnson TR, Klepinger DH (1994) Experimental evidence on Unemployment Insurance work-search policies. J Hum Resour 29(3):695-717

Lane P, Casebourne J, Lanceley L, Davies M (2011) Lone parent obligations: work, childcare and the Jobseeker's Allowance regime. Department for Work and Pensions, Research Report 782. HMSO, Norwich

Manning A (2009) 'You can't always get what you want: the impact of the UK Jobseeker's Allowance. Labour Econ 16:239-250

Martin JP, Grubb D (2001) What works for whom? A review of OECD countries experiences with active labour market policies. OECD Working Paper 14. OECD, Paris

Moffitt R (2008) Institute for Labor Market Policy Evaluation Working Paper 2008-13. Uppsala

OECD (2007) Babies and Bosses: Reconciling Work and Family Life. OECD, Paris

OECD (2012) OECD Stat Abstracts: Real Hourly Minimum Wages. OECD, Paris, http://stats.oecd.org/

Petrongolo B (2009) What are the long term effects of UI? Evidence from the UK JSA reforms. J Public Econ 93:1234-1253

Van den Berg GJ (2001) Duration models: specification, identification and multiple durations. In: Heckman J, Leamer E (eds) Handbook of Econometrics Volume 5. Elsevier/North Holland, Amsterdam

doi:10.1186/2193-9004-2-3

Cite this article as: Fok and McVicar: Did the 2007 welfare reforms for low income parents in Australia increase welfare exits?. IZA Journal of Labor Policy 2013 2:3. 